\title{
Nucleotide sequences of the $p b p X$ genes encoding the penicillin-binding proteins $2 x$ from Streptococcus pneumoniae R6 and a cefotaxime-resistant mutant, C506
}

\author{
G. Laible, ${ }^{1}$ R. Hakenbeck, ${ }^{1 *}$ M. A. Sicard, ${ }^{2}$ B. Joris ${ }^{3}$ \\ and J.-M. Ghuysen ${ }^{3}$ \\ ${ }^{1}$ Max-Planck Institut für Molekulare Genetik, Ihnestrasse \\ 73, D-1000 Berlin 33, FRG. \\ ${ }^{2}$ Université Paul Sabatier, CNRS, 118 route de \\ Narbonne, Toulouse 31062, France. \\ ${ }^{3}$ Departement de Microbiologie, B6, Université de \\ Liège, Sart Tilman, B-4000 Liège, Belgium.
}

\section{Summary}

Development of penicillin resistance in Streptococcus pneumoniae is due to successive mutations in penicillin-binding proteins (PBPs) which reduce their affinity for $\beta$-lactam antibiotics. PBP2x is one of the high- $M_{r}$ PBPs which appears to be altered both in resistant clinical isolates, and in cefotaxime-resistant laboratory mutants. In this study, we have sequenced a 2564 base-pair chromosomal fragment from the penicillin-sensitive $S$. pneumoniae strain R6, which contains the PBP2x gene. Within this fragment, a 2250 base-pair open reading frame was found which coded for a protein having an $M_{r}$ of $82.35 \mathrm{kD}$, a value which is in good agreement with the $M_{\mathrm{r}}$ of $80-85 \mathrm{kD}$ measured by SDS-gel electrophoresis of the PBP2x protein itself. The $\mathbf{N}$-terminal region resembled an unprocessed signal peptide and was followed by a hydrophobic sequence that may be responsible for membrane attachment of PBP2x. The corresponding nucleotide sequence of the PBP2x gene from C504, a cefotaximeresistant laboratory mutant obtained after five selection steps, contained three nucleotide substitutions, causing three amino acid alterations within the $\beta$-lactam binding domain of the PBP2x protein. Alterations affecting similar regions of Escherichia coli PBP3 and Neisseria gonorrhoeae PBP2 from $\beta$-lactam-resistant strains are known. The penicillin-binding domain of PBP2x shows highest homology with these two PBPs and S. pneumoniae PBP2b. In contrast, the $\mathrm{N}$-terminal extension of PBP2x has the

Received 4 April, 1989; revised 20 June, 1989. "For correspondence. Tel. (030) 8307340; Fax (030) 8307382 highest homology with E. coli PBP2 and methicillinresistant Staphylococcus aureus PBP2'. No significant homology was detected with PBP1a or PBP1b of Escherichia coli, or with the low-Mr PBPs.

\section{Introduction}

Penicillin-binding proteins (PBPs), the target enzymes for $\beta$-lactam antibiotics, are minor components of the bacterial cytoplasmic membrane. They function in the late steps of murein biosynthesis, and therefore their active centre is on the outer surface of the cytoplasmic membrane. $\beta$-lactams inactivate the PBPs by acylating an essential serine residue in the active site of these proteins. Whereas inhibition of low- $M_{r}$ PBPs, which are D-alanyl-Dalanine-carboxypeptidases, can be tolerated by the bacteria, inhibition of high- $M_{\mathrm{r}}$ PBPs, which are assumed to be transpeptidases, is lethal to the cells. Based on the sequences of their penicillin-binding domains, all PBPS are thought to be related to each other; they form, together with the penicillin-hydrolysing enzymes ( $\beta$-lactamases), a superfamily of active-site serine, penicillin-recognizing proteins (Joris et al., 1988). Much, however, remains to be learned about the evolutionary relationships among the PBPs, primarily because of the lack of information about the sequences and overall structures of the high- $M_{r}$ PBPs of different species.

Streptococcus pneumoniae contains six PBPs (Hakenbeck et al., 1986). The five high- $M_{r}$ PBPs $1 \mathrm{a}, 1 \mathrm{~b}, 2 \mathrm{x}, 2 \mathrm{a}$ and $2 \mathrm{~b}$, ranging from 92 to $78 \mathrm{kD}$, are of unknown function, whereas the $43 \mathrm{kD}$ low- $M_{\mathrm{r}}$ PBP3 acts in vitro as a D,D-carboxypeptidase (Hakenbeck and Kohiyama, 1982). Penicillin resistance in pneumococci can be acquired by the stepwise accumulation of mutations in at least the three high-Mr PBPs 1a, 2x and $2 \mathrm{~b}$ (Hakenbeck et al., 1980; Zighelboim and Tomasz, 1980; Hakenbeck et al., 1988). In earlier papers, only five PBPs were detected using different SDS-PAGE systems, and alterations were also shown to occur in a so-called PBP2a; however, we believe that this protein was actually PBP2x. Penicillin resistance can also be obtained by the stepwise transformation of sensitive strains using the DNA from resistant strains that have been isolated in clinics or produced in the laboratory 
(Shockley and Hotchkiss, 1970). In this process, the transformants successively acquire the altered PBPs of the donor strain (Zighelboim and Tomasz, 1980). Since these PBP alterations lead to a decrease in affinity for $\beta$-lactams, characterization of the mutations involved will help to identify the protein regions responsible for the interaction with $\beta$-lactam antibiotics.

The problems of analysing these mutations in clinical isolates is at least two-fold: the strains are not isogenic, and the mechanism responsible for evolution of lowaffinity PBPs is not known. Gene sequencing has revealed that PBPs from penicillin-resistant clinical isolates of Neisseria gonorrhoeae (PBP2) (Spratt, 1988) and S. pneumoniae (PBP2b) (Dowson et al., 1989) have extensive alterations in their primary structure, thus aggravating the identification of those mutations that contribute to the decrease in penicillin affinity. We have therefore isolated a series of spontaneous, independent, laboratory mutants with increasing resistance to either piperacillin or cefotaxime (Laible and Hakenbeck, 1987). Cefotaxime resistance leads to affinity changes primarily of PBP2a and PBP2x. Using cefotaxime resistance as selective marker in transformation experiments, we have been able to identify the DNA coding for PBP2x. The gene and surrounding regions were sequenced, and the mutations responsible for cefotaxime resistance in the laboratory mutant C506 were identified. The deduced amino acid sequences of PBP2x were used for comparative analysis with PBPs of other bacterial species.

\section{Results and Discussion}

\section{Isolation of the $\mathrm{pbpX}$ gene of $\mathrm{S}$. pneumoniae}

In the cefotaxime-resistant mutant, C506, PBP2x and PBP2a have reduced affinity for $\beta$-lactams (Laible and Hakenbeck, 1987). The strategy used for cloning the $p b p X$ gene was based on identification of DNA fragments capable of transforming penicillin-sensitive strains 801 (which carries a hex- mutation) or R6 to cefotaxime resistance. No attempts were made to clone the gene directly into $E$. coli since unstable clones are frequently observed probably because of promoter-bearing regions in the AT-rich pneumococcal DNA (Stassi and Lacks, 1982).

After BamHI-digestion of chromosomal C506 DNA, the 2.3-3.6 kb DNA fraction could transform strain 801 to cefotaxime resistance $\left(0.06 \mu \mathrm{g} \mathrm{ml}^{-1}\right)$ and was cloned into plasmid pSP2. pSP2, carrying an erythromycin resistance marker, is stable in pneumococci only as a recombinant plasmid because of long inverted repeats (Prats et al., 1985). After transformation of 801 with the recombinant plasmids, no transformants could be selected using

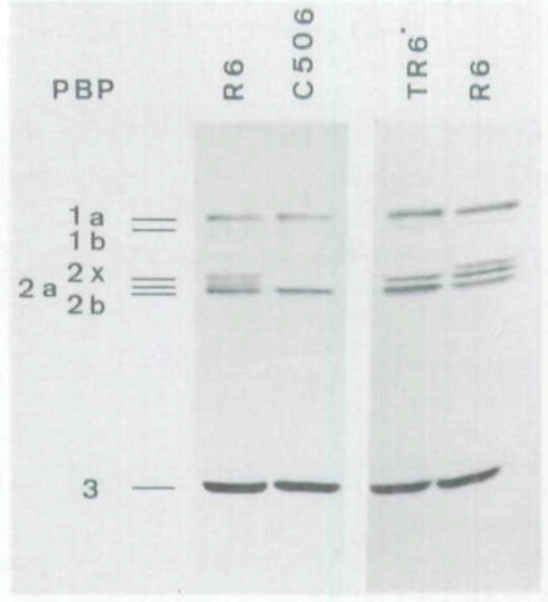

Fig. 1. PBPs in a cefotaxime-resistant transformant of S. pneumoniae R6. PBPs in cell lysates were labelled with [3 $\mathrm{H}]$-propionyl ampicillin, separated on SDS-PAGE, and visualized after fluorography. For comparison, the PBP pattern of the parent strain R6 and the cefotaximeresistant mutant C506 is shown in addition to the one found in a cefotaxime-resistant transformant TR6. TR6 has been obtained after transformation of R6 with the $0.8 \mathrm{~kb}$ EcoRI/Bam HI fragment (carrying the cefotaxime resistance marker of (C506) and selection on $0.06 \mu \mathrm{g} \mathrm{ml}^{-1}$ cefotaxime.

erythromycin plus cefotaxime, indicating that cefotaxime resistance is not expressed. Therefore, erythromycinresistant transformants were isolated and replated on plates containing cefotaxime alone. Clones containing recombinant pSP2 carrying the cefotaxime resistance marker should be able to produce cefotaxime-resistant colonies at low frequency because of homologous recombination with the chromosomal $p b p X$ wild-type gene. Fifteen out of 200 erythromycin-resistant transformants produced cefotaxime-resistant colonies and contained the same pSP2 derivative, pPG1, with a $2.6 \mathrm{~kb}$ Bam HI insert. The cefotaxime-resistant transformants in which part of the genome had been replaced by recombination with the $2.6 \mathrm{~kb}$ fragment of C506 contained a low-affinity PBP2x (Fig. 1), demonstrating that part or all of the $p b p X$ gene is located on PPG1.

Digestion of the $2.6 \mathrm{~kb}$ BamHI insert with EcoRI produced two fragments. After transformation of the 801 recipient strain by either one of the fragments, only the smaller one $(0.8 \mathrm{~kb})$ yielded cefotaxime resistance. Sequencing of this $0.8 \mathrm{~kb}$ EcoRI-Bam HI fragment revealed an open reading frame which terminated 60 nucleotides upstream from the $E c O R I$ site and continued through the $\mathrm{BamHI}$ site, indicating that the $\mathrm{C}$-terminal part of the PBP2x gene had been cloned.

The wild-type $p b p X$ gene was then isolated in two steps using the $2.6 \mathrm{~kb} \mathrm{BamHI}$ fragment from C506. In the first step, the $1.8 \mathrm{~kb} E c o R \mathrm{R} / \mathrm{Bam} \mathrm{HI}$ portion of this fragment, downstream from $p b p X$, was inserted into $\mathrm{pR} 28$, and this construct, pCG4, was inserted into the chromosome of strain 801 by homology-dependent integration (Fig. 2). A 


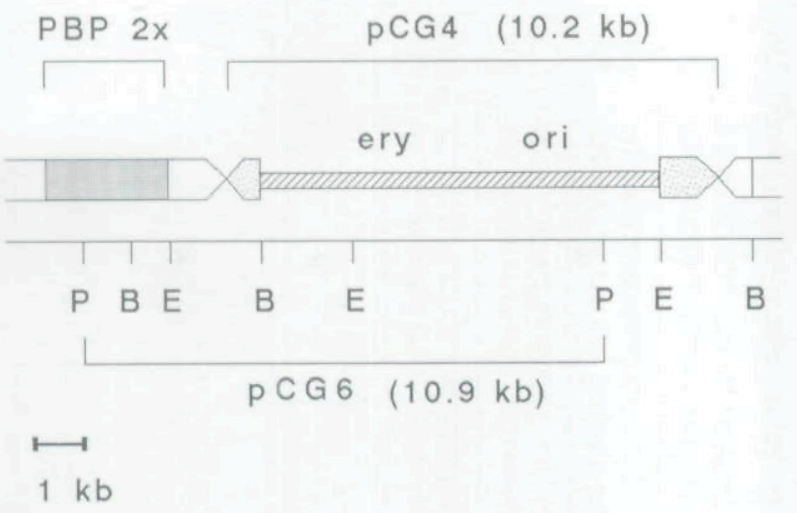

Fig. 2. Schematic illustration of the isolation of DNA fragments of the PBP2x gene by vector integration into the chromosome. Integration of plasmid pCG4 into the chromosome of strain 801 was forced by selecting erythromycin-resistant transformants. Recombination occurred between the EcoRI/BamHI $1.8 \mathrm{~kb}$ C506 insert (dotted part) of pCG4 and the homologous chromosomal DNA (white) in strain 801. pCG6 was isolated after digestion with PstI restriction enzyme, ligation, and selection of erythromycin-resistant $E$. coli transformants. Indicated are the positions of the origin (ori) and erythromycin resistance gene within the vector part of pCG4 (hatched region).

second recombinant plasmid, pCG6, was then isolated from the chromosome using Pstl restriction endonuclease. In the second step, the $0.4 \mathrm{~kb}$ EcoRV-Pst। fragment was removed from pCG6 and was used as a hybridization probe on R6 DNA digested with Dral/ EcoRV. A $2.4 \mathrm{~kb}$ fragment was found, which presumably carried the promoter region. It was cloned into plasmid pJDC9, in which strong terminators surrounding the cloning site should facilitate cloning of pneumococcal promoter sequences into $E$. coli (Chen and Morrison, 1987).

The restriction endonuclease cleavage map of the $p b p X$ region is shown in Fig. 3. The 2250-nucleotide open reading frame of the $p b p X$ gene encoded 750 amino acid residues (Fig. 4). It was preceded by an open reading frame, and another open reading frame started almost immediately after termination of the $p b p X$ gene (Fig. 3). No other long open reading frames were found. Potential candidates for Shine-Dalgarno and promoter sequences were identified using $E$. coli consensus sequences. A putative rho-independent terminator region was found following the terminator codon, TAA (Fig. 4).

No differences between the nucleotide sequences of the $p b p X$ genes of strains R6 and 801 were detected. The sequence obtained from mutant C506 differed in three nucleotides from R6 or 801, changing Met289 into Thr and the closely linked Gly597 and Gly601 into Val597 and Asp601, respectively (Fig. 4). Between the $N$ terminus and Met289, no mutations were found even in more highly resistant mutants derived from C506.

The codon usage was very similar to that of the gene encoding the pneumococcal high- $M_{r}$ PBP2 $b$, which has been partly sequenced recently (Dowson et al., 1989), but not to the highly expressed $/ y t A$ gene coding for the major autolysin of S. pneumoniae (Garcia et al., 1986) (not shown). Marked differences were found in the codon usages for Gly, Asp, Tyr, Phe, Ser and His, probably reflecting the more frequent use of modulator codons in weakly expressed genes, as has been suggested for $E$. coli PBPs (Asoh et al., 1986).

The $M_{r}$ of PBP2x, according to the derived amino acid sequence, is $82.35 \mathrm{kD}$, a value which is in agreement with an $M_{r}$ of approximately $80-85 \mathrm{kD}$, as derived from SDSgel electrophoresis.

\section{Conserved boxes in the amino acid sequence of PBP2x}

On the basis of homology searches and amino acid alignment, several conserved regions have been identified among the $\beta$-lactamases, low- $M_{\mathrm{r}}$ PBPs and penicillinbinding domains of the high- $M_{r}$ PBPs (Joris et al., 1988).
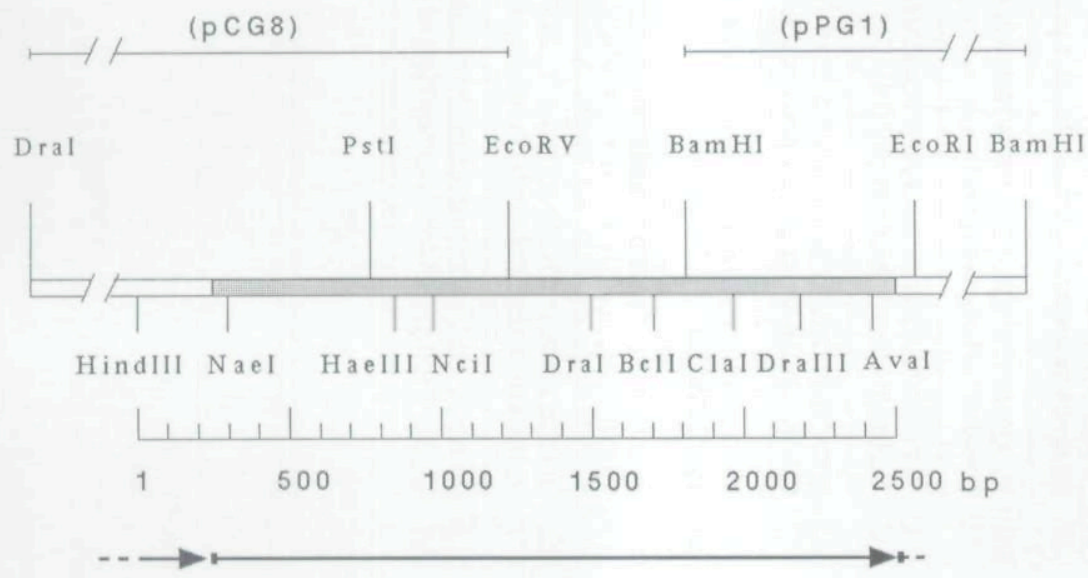

Fig. 3. Restriction map of the $p b p X$ region. Shown here are the restriction sites used for cloning various parts of the PBP2x gene as indicated in pPG1, pCG6 and pCG8, and further unique restriction sites (lower part). The arrows indicate open reading frames between the HindIII and EcoRI sites. Dotted area: the region coding for PBP2x. 


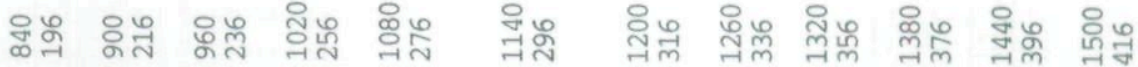
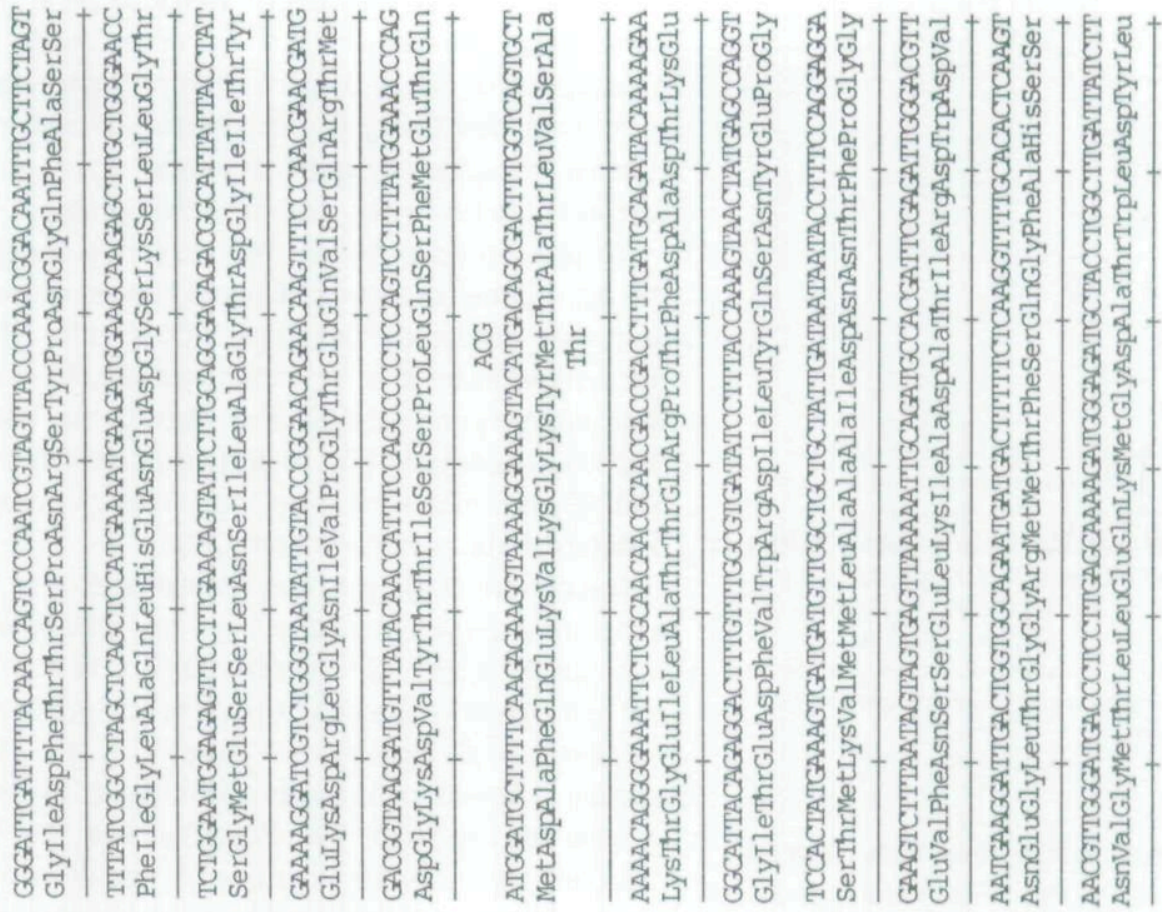

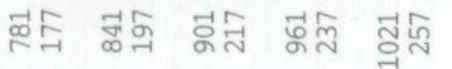
어요

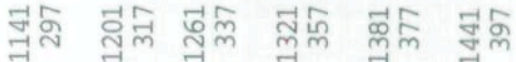

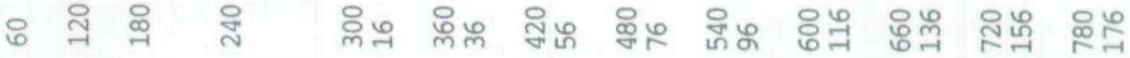

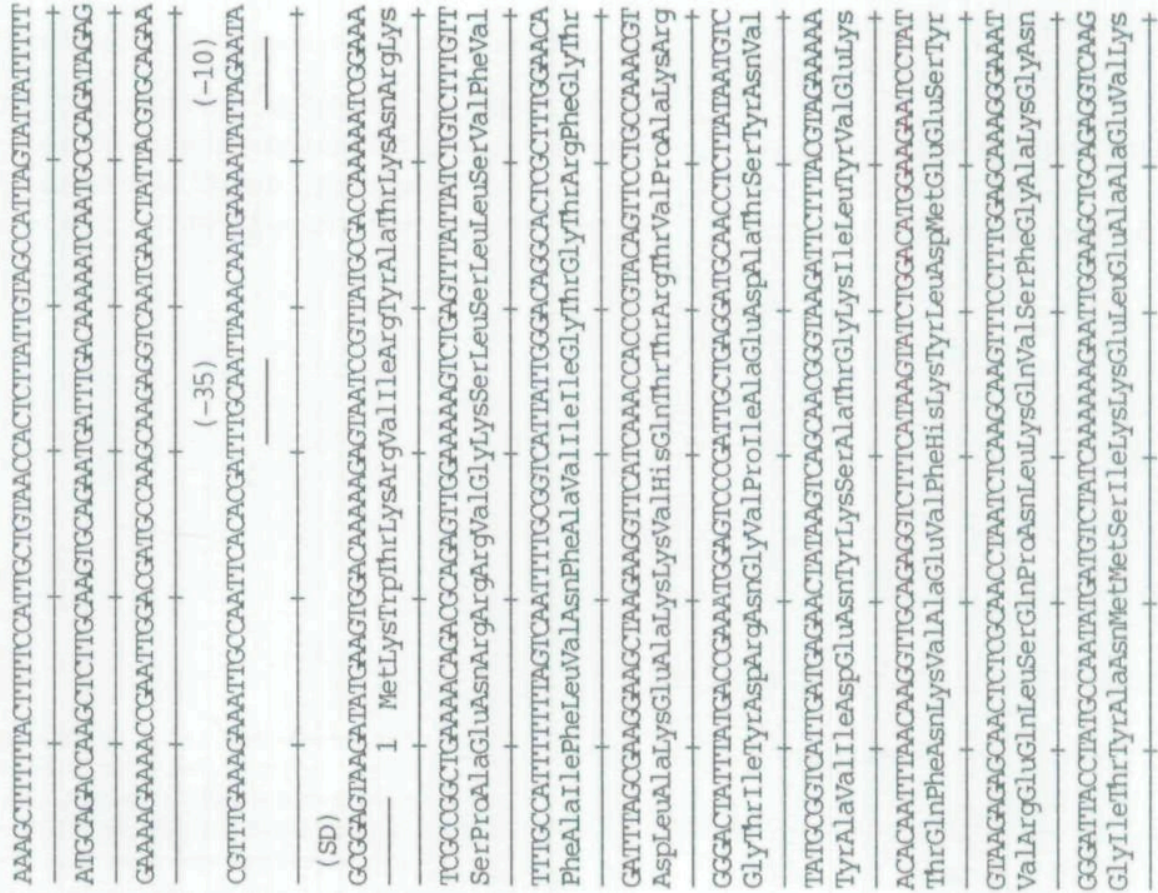

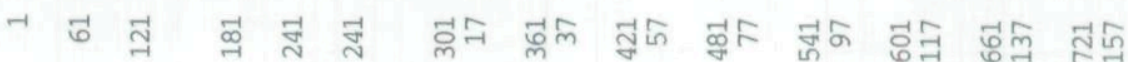




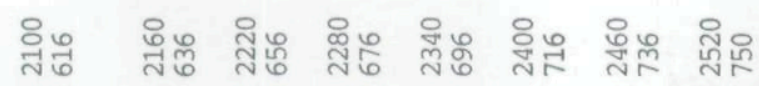

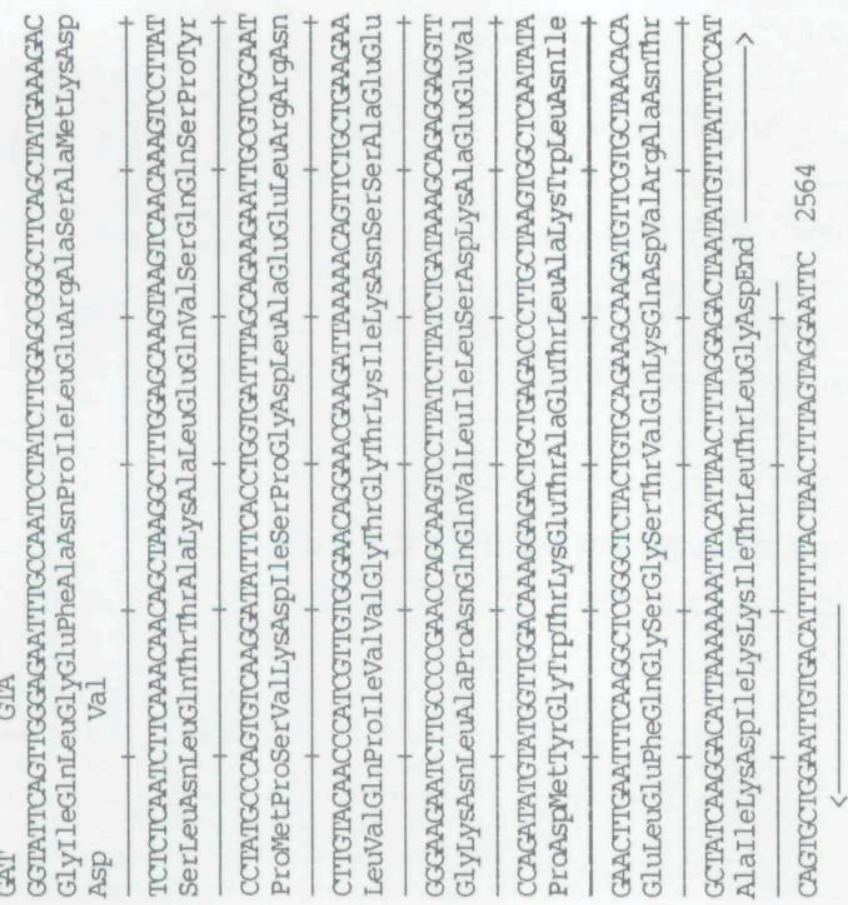

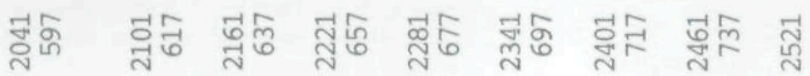

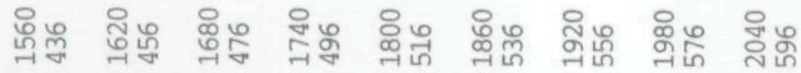

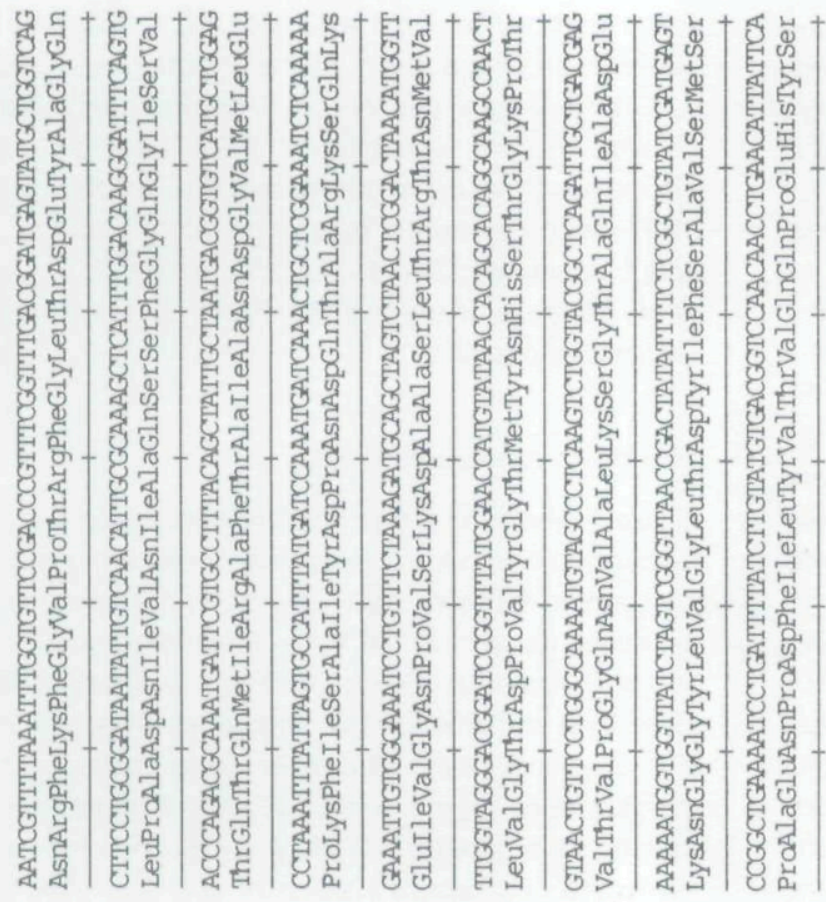

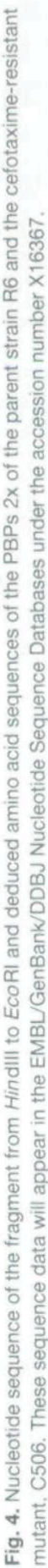

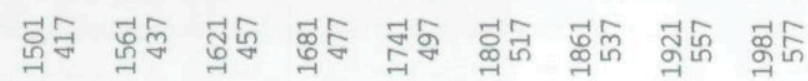


a)

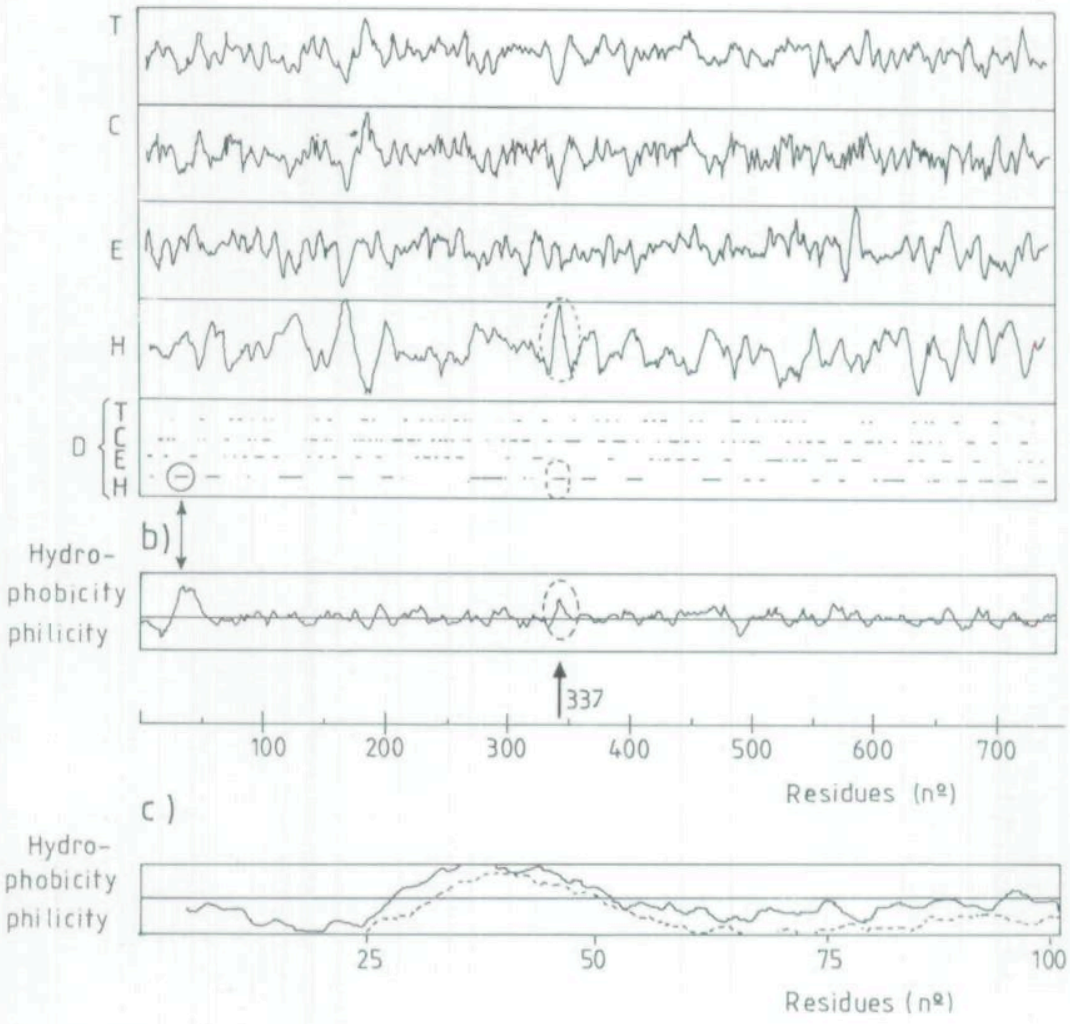

Fig. 5. Predicted secondary structures and hydrophobicity $(\mathrm{a}, \mathrm{b})$ and detection of a transmembrane segment at position $30-40$ (c) in the S. pneumoniae PBP2x. T: turn; C: coil; E: extended; $\mathrm{H}$ : $\alpha$-helix; D: decision. Programs used (a) Garnier et al. (1978); (b): Kyte and Doolittle (1982); (c): Kyte and Doolittle (1982); Engelman et al. (1986). The position of the active-site serine 337 is indicated.
The active-site serine is always part of the sequence SXXK (box II) and, at a certain distance from the $C$ terminus, one of the triad KTG, KSG or HTG (box VII) can be found. Recently, an SXN motif was identified on the carboxyterminal side of the active-site serine (Spratt and Cromie, 1988).

In S. pneumoniae PBP2x, STMK $337-340$ is thought to contain the active-site serine and KSG $547-549$ is assumed to be the conserved triad HTG/KTG/KSG for the following reasons. (i) $\mathrm{S} 337$ is at the amino terminus of a hydrophobic stretch with a high $\alpha$-helix potential (Fig. 5). The occurrence of the active-site serine at the end of an $\alpha$-helix is expected from the three-dimensional data obtained from the crystal structure of Streptomyces R61 PBP (Kelly et al., 1988). (ii) S395SN is 58 amino acids downstream of the STMK-sequence, corresponding to the reported 47-62 amino acid distance in other high- $M_{r}$ PBPS (Spratt and Cromie, 1988). (iii) The size of the stretch S337TMK to K547SG (i.e. 210 amino acids) is that expected for a penicillin-binding domain (Table 1). In this table, and as proposed by Joris et al. (1988), the penicillinbinding domain of the PBPS is defined as a polypeptide stretch that starts 60 residues (or less) upstream of the active-site serine and terminates 60 residues (or less) downstream of the $\mathrm{H}$ or $\mathrm{K}$ of the conserved box VII. This pattern allows definition of an amino-terminal extension and a carboxy-terminal extension on both sides of the penicillin-binding domain. All the $\beta$-lactamases of classes $\mathrm{A}, \mathrm{C}$ and $\mathrm{D}$ lack any $\mathrm{N}$ - or $\mathrm{C}$-terminal extension (not shown). The low- and high- $M_{r}$ PBPs have a $C$-terminal extension of varying length, except the Streptomyces R61 $\mathrm{PBP}$, which is excreted during growth (Duez et al., 1987) and, interestingly, the PBP2b of S. pneumoniae (Dowson et al., 1989). Only the high- $M_{r}$ PBPs have a long aminoterminal extension.

\section{Membrane topology of PBP2x}

Figure 5 reveals that one predominant region with a high hydrophobicity index occurs close to the amino terminus. The amino-terminal 100 amino acid region was reexamined using both the Kyte-Doolittle procedure (1982) and the Engelman-Steitz-Goldman program (1986) for identifying transmembrane segments. The two profiles (Fig. 5) strongly suggest that PBP2x is anchored into the membrane by amino acids L30-148. It should be noted that the same stretch has a high $\alpha$-helix potential according to the program of Garnier et al. (1978). This hydrophobic portion is preceded by a terminal hydrophilic as well as a basic region (known features of signal peptides) 
(von Heijne, 1985). On the basis of the amino acid sequence, no cleavage site for a signal peptidase was found. We therefore assume that the mature form of PBP2x contains an unprocessed signal sequence followed by a membrane-anchoring segment, as has been shown for E. coli PBP1b (Spratt et al., 1987) and PBP2 (Asoh et al., 1986). In contrast, E. coli PBP3 is probably processed after synthesis (Nakamura et al., 1983) and membrane binding might be mediated through modification of a cysteine residue with a lipid moiety (Hayashi et al., 1988). If the membrane topology proposed for PBP2x is correct, then that portion of the amino-terminal extension which occurs upstream of the penicillin-binding domain and which might have some enzymatic function would be the 227 amino acid stretch, T50-M277.

\section{Homology searches}

The amino acid sequences of all the PBPs listed in Table 1 were compared pair-wise using the Goad and Kanehisa procedure (1982) and the SEQHP and SEQDP programs (for more details, see Joris et al., 1988). For each pair of PBPs, the amino-terminal extensions (for the high- $M_{r}$ PBPs) and the penicillin-binding domains, as defined in Table 1, were analysed separately. The procedure yields a score and a standard deviation unit (SDU). The more negative the score, the better the homology. An SDU value of five or higher indicates a statistically significant homology. The results of this analysis are shown in Fig. 6 . It should be noted that part of the $\mathrm{N}$-terminal sequence of pneumococcal PBP2b is absent.
The data show that PBP2x is related to all the other high-Mr PBPs, with the exception of E. coli PBPs 1a and 1b. These two proteins are highly homologous in their amino-terminal extensions, as has been reported previously (Broome-Smith et al., 1985; Joris et al., 1988), and both are known to perform transglycosylation in vitro (Tomioka et al., 1982; Nakagawa et al., 1984). No significant homology between high- and low- $M_{r}$ PBPs was detected. Interestingly, the penicillin-binding domain of PBP2x is especially closely related to those of $E$. coli PBP3, N. gonorrhoeae PBP2 and S. pneumoniae PBP2b. In contrast, the amino-terminal extension of PBP2x is closely related to those of E. coli PBP2 and methicillinresistant $S$. aureus $\mathrm{PBP}^{\prime}$. It can be speculated that the $\mathrm{N}$-terminal extension and the penicillin-binding domain of PBP2x have evolved independently from each other.

\section{Comparison with E. coli PBP3}

The two sequences of PBP2x and E. coli PBP3 have been aligned using the BESTFIT program (Fig. 7). In this alignment, the only short gap introduced in the sequence of PBP2x is N441. . 1442. The two amino-terminal extensions (PBP2x, $1 \rightarrow 277$ ) contain 48 identities $(17 \%)$ and two highly homologous stretches. The two penicillin-binding domains $(278 \rightarrow 607)$ contain 80 identities $(24 \%)$ and seven highly homologous stretches.

The homology found between these two proteins does not necessarily indicate any similarity in their respective enzymatic activity in vivo, or affinity for $\beta$-lactams. The high in vivo affinity of the $E$. coli PBP3 for aztreonam

Table 1. Amino-terminal extension, penicillin-binding domain and carboxy-terminal extension of PBPS.

$\begin{gathered}\text { Amino-terminal } \\ \text { extension }\end{gathered}$
$\mathrm{H}_{3}{ }^{*} \mathrm{~N} \stackrel{\text { Penicillin-binding Domain }}{\longleftarrow} \mathrm{S}^{*} \mathrm{XXK} \longrightarrow$

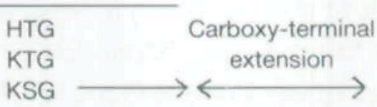

Low-M, PBPS

Streptomyces R61

B. subtilis 5

E. coli 5

High-M, PBPS

E. coli $1 \mathrm{~A}$

$1 \mathrm{~B}$

2

3

S. aureus 2 '

N. gonorrhoeae 2

S. pneumoniae $2 \mathrm{x}$

S. pneumoniae $2 b^{a}$
0

0
0
0

0

$\begin{array}{ll}(404) & 405 \\ (449) & 450 \\ (269) & 270 \\ (246) & 247 \\ (344) & 345 \\ (249) & 250 \\ (276) & 277 \\ (' 131 ') & 132\end{array}$

$\begin{array}{ll}62 & (236) \\ 36 & (191)\end{array}$

$44 \quad$ (169)

\begin{tabular}{lll}
465 & $(251)$ & 716 \\
510 & $(188)$ & 698 \\
330 & $(213)$ & 544 \\
307 & $(187)$ & 494 \\
405 & $(194)$ & 599 \\
310 & $(187)$ & 497 \\
337 & $(210)$ & 547 \\
192 & $(229)$ & 421 \\
\cline { 2 - 3 } & average: 205 &
\end{tabular}

298

227

213

349

287

273

776

758

604

554

659

557

607

481

$\begin{array}{cc}0 & 349 \\ (125) & 412 \\ (101) & 374\end{array}$

(101)

412
374

$\begin{array}{cc}(74) & 850 \\ (86) & 844 \\ (26) & 630 \\ (34) & 588 \\ (111) & 770 \\ (24) & 581 \\ (143) & 750 \\ 0 & 481\end{array}$

References of sequences shown: Streptomyces R61 (Duez et al., 1987); B. subtilis PBP5 (Todd et al., 1986); E. coli PBP5 (Broome-Smith et al., 1983); E. coli PBPs 1A and 1B (Broome-Smith et al., 1985); E. coli PBP2 (Asoh et al., 1986); E. coli PBP3 (Nakamura et al., 1983); S. aureus PBP2' (Song et al., 1987); N. gonorrhoeae PBP2 (Spratt, 1988); S. pneumoniae PBP2b (Dowson et al., 1989).

a. Only 131 amino acid residues of the amino-terminal extension are known. 

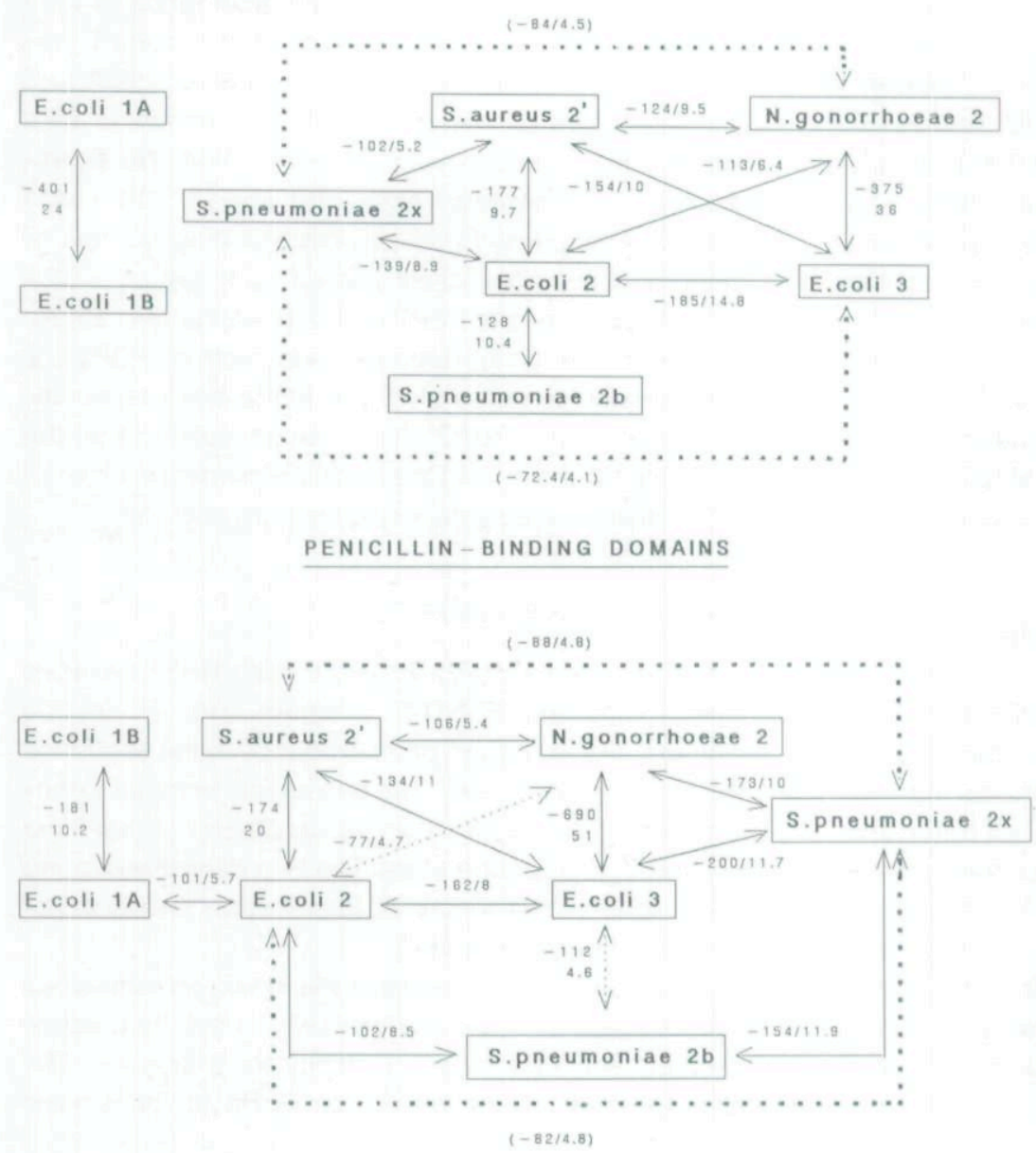

Fig. 6. Relationship between the S. pneumoniae PBP2x and other high-Mr. PBPs of known primary structure. For each pair of PBPs, the aminoterminal and penicillin-binding domains were analysed separately using the Goad and Kanehisa procedure (1982). Dotted lines indicate a relationship of marginal significance. (binding occurs at $0.01 \mu \mathrm{g} \mathrm{ml}^{-1}$ ) (Briese et al., 1988) was not found with the pneumococcal PBP $2 \times\left(1 \mu \mathrm{g} \mathrm{ml}^{-1}\right.$ and higher), and the related pneumococcal PBP2b does not bind aztreonam at all (Hakenbeck et al., 1987).

\section{Analysis of mutations in C506}

The three point mutations found in PBP2x of the cefotaxime-resistant mutant, C506 (i.e., M289 $\rightarrow$ T; G597 $\rightarrow$ D; $\mathrm{G} 601 \rightarrow \mathrm{V}$ ) are located at both ends of the penicillin-binding domain (Figs 4 and 7). We believe that the mutations, or some of them, are responsible for $\beta$-lactam resistance in that they decrease penicillin affinity or stabilize an already mutated PBP2x. The contribution of the individual mutations to $\beta$-lactam resistance is currently under investigation. Since PBP2x appears to be an essential protein, the mutations are unlikely to affect its actual enzymatic function.

The PBP2x mutations in C506 occur close to amino acid stretches that are highly homologous to other high- $M_{r}$ PBPs (Fig. 8). The Val284 to Asp313 sequence of PBP2x shares homology even with the corresponding regions of the $E$. coli PBPs $1 \mathrm{a}$ and $1 \mathrm{~b}$, which in turn reveal high homology with that of the E. coli PBP2 (see also Fig. 6). It is striking that the mutated positions found in PBP2x are almost identical to those found in E. coli PBP3 of low-level cefalexin-resistant mutants isolated after mutagenesis $(\mathrm{A} 257 \rightarrow \mathrm{V} ; \mathrm{V} 545 \rightarrow \mathrm{I})$, and that among the mutations inactivating PBP3 without impairing its ability to bind penicillin, substitutions in G542 as well as A547 were found (Hedge and Spratt, 1985a; 1985b) (Fig. 8). This region also corresponds to a peptide stretch that appeared highly mutated in the resistant gonococcal strains (Spratt, 1988). It is likely that the homologous peptide stretches belong to preserved three-dimensional structures that occupy important positions, and that the mutations fall into nearby variable loops important for access of $\beta$-lactam antibiotics. 
2x 6 RVIRYATKNRKSPAENRRRVGKSLSLLSVFVFAIFLUNFAVIIGIGIRPG 55 31 MKAAAKTOKPKRQEEHANFISWRFALLOGCILLALAFLLGRVAWLOVISP 50 2x 56 TDLAKEAKKVHHCITIRTVPAKRGIIYDRNGVPIAEDATSYNVYAVIDENYK 105

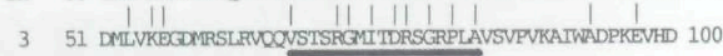
2X 106 SATGKILYVEKKIQFNKVAEVFHKYLDMEES SYVREQLSQPNLKQVSFGAKG 155

3101 AGGISVGDFWKALANALNIPLDQLSARINANPKGR............FIYLA 143

2X 156 NGITYANMSIKKEI EAAEVKGIDFTTSPNRSYPNCQFASSFIGLAQLHE 205 3144 RQVNPDMADYIKKLK.....LPGIHLREESRRYYPSGEVIAHLIGFINVDS 186 2X 206 NEDGSKSLLGTSGMESSLNSILAGIDGIITYYEDRLGNIVPGIEQVSQRT 255

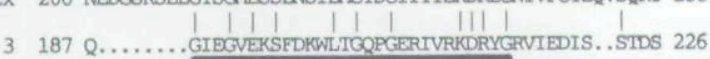
2X 256 MDGKDVYTTISSPLOSFMETQMDAFQEKVKGKYMTATLVSAKTGEILATT 305 | || |

3227 OAAHNLALSIDERLOALVYRETNNAVAFNKAESGSAVLVDVNIGEVLAMA 276

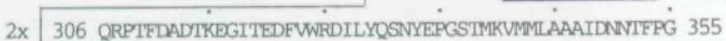
3 \begin{tabular}{ccc|c|c|c|}
\hline & $\mid$ & $\mid$ & $\mid$
\end{tabular} 3 3 326 NSVLNTIPYRINGHEIKDVARYSELTILTG...... VIOKSSSNVGSKLAL 369 $2 \times 406$ KMGDATWLDYLLNRFKFGVPIRFGLIDEYAQQLPADN... IUNIAQSSEGQ 452 | | || | | || | | | | ||| 3370 AMPSSALVDIYSRPGLGKATNLGLVGERSGLYPOKOFWSDIERATFSFGY 419 2x 453 GISVIQTIOMIRAFTAIANDGUVMLEPKFISAIYDPNDQIARKSQKETVGNP 502

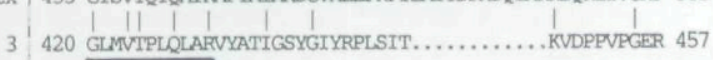

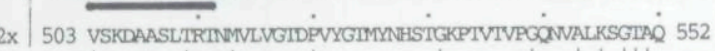

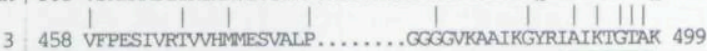

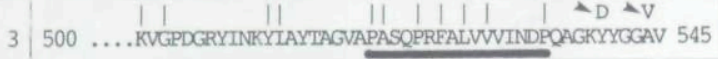
2x 603 FANPILERASAMINDSLNLOTITAKALEQVSSQOSPYPMPSVKDISPGDLAEE 652 3546 SAPVIFATMGGVLRTIMIIEPDALTTGDKNEFVINOGEGIGGRS* ...... 589

Fig. 7. Alignment of S. pneumoniae PBP2x with E. coli PBP3 using the BESTFIT program. Indentical amino acids are marked. Indicated are sequences of high homology (see text for details) and the penicillinbinding domain of the PBPs. Arrows: amino acid alterations of PBP2x from strain C506.

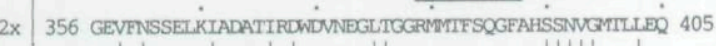
3458 VFPESTVRTVVHMMESVALP.......... . . . $2 \mathrm{x} 553$ IADEKNGGYLVGLTDYIFSAVSMSPAENPDFILYVIVDQPEHYSGIQLGE 602

\section{Experimental procedures}

\section{Bacterial strains, growth conditions, plasmids and bacteriophages}

S. pneumoniae R6 is a penicillin-sensitive, non-encapsulated laboratory strain (Ottolenghi and Hotchkiss, 1962) with an MIC value for cefotaxime of $0.02 \mu \mathrm{g} \mathrm{ml}^{-1}$. The other pneumococcal strains used are derivatives of strain R6. C506 is a spontaneous cefotaxime-resistant mutant isolated after five selection steps on increasing concentrations of cefotaxime (MIC for cefotaxime: $1.28 \mu \mathrm{g} \mathrm{ml}^{-1}$ ) (Laible and Hakenbeck, 1987). Strain 801 is an R6 derivative carrying a hex mutation and is therefore defective in the mismatch repair process (Levèfre et al., 1979). Cells were cultivated in C-medium supplemented with $0.2 \%$ yeast extract (Lacks and Hotchkiss, 1960) at $37^{\circ} \mathrm{C}$ without aeration. E. coli JM103 (Messing et al., 1981) was used for growth of phagescript SK (Stratagene: San Diego, CA) and M13mp8/mp9 phages (Messing and Vieira, 1982), and E. coli DH5 was used for propagation of E. coli plasmids. Plasmids pJDC9 (Chen and Morrison, 1987), pSP2, which can be used for direct selection of recombinant plasmids (Prats et al., 1985), and pR28, which cannot be maintained autonomously in pneumococci (Méjean et al., 1981) have been described.

\section{Transformation}

Transformation of $S$. pneumoniae strains was carried out according to Tiraby and Fox (1974). Cefotaxime-resistant transformants

\begin{tabular}{|c|c|c|c|c|c|}
\hline \multirow{2}{*}{\multicolumn{2}{|c|}{ S.p. $2 x$}} & $(284$ & $\stackrel{\text { VKGKYMTATL }}{\prime}$ & VSAKTGEILA & TTQRPTFDAD \\
\hline & & & $r$ & $\star * * * * *$ & * * \\
\hline \multirow[t]{2}{*}{ E.c. } & 3 & (255) & NKAESGSAVL & VDVNTGEVLA & MANSPSYNPN \\
\hline & & & * & $\star * * * * *$ & ** \\
\hline \multirow[t]{2}{*}{ N.g. } & 2 & $(258)$ & HQAKAGTVVV & LDARTGEILA & LANTPAYDPN \\
\hline & & & * & $\star \star * * \star *$ & $* \star *$ \\
\hline \multirow[t]{2}{*}{ E. C. } & 2 & $(266)$ & LAGSRAAVVV & TDPRTGGVLA & LVSTPSYDPN \\
\hline & & & * & $* * \quad * *$ & $* * *$ \\
\hline \multirow[t]{2}{*}{ s.a. } & 2 , & $(342)$ & MKNDYGSGTA & IGPQTGELLA & LVSTPSYDVY \\
\hline & & & & $* * * \cdots$ & $* * *$ \\
\hline \multirow[t]{2}{*}{ S.p. } & $2 \mathrm{~b}$ & (144) & KYSEGVYAVA & LNPKTGAVLS & MSGIKHDLKT \\
\hline & & & * & ** $\quad$ * & \\
\hline \multirow[t]{2}{*}{ E.c. } & $1 \mathrm{~A}$ & $(422)$ & VPEVNSALVS & INPQNGAVMA & LVGGFDFNQS \\
\hline & & & n & $* \quad *$ & \\
\hline E.c. & $1 \mathrm{~B}$ & $(467)$ & LSDLETAIVV & VDRFSGEVRA & MVGGSEPQFA \\
\hline
\end{tabular}

The PBP2b gene of one highly penicillin-resistant pneumococcal strain contains a vast number of nucleotide changes (74) coding for 17 amino acid substitutions (Dowson et al., 1989). Similarly, a highly altered PBP gene occurs in resistant gonococci (Spratt, 1988). It would be of interest to search in the pneumococcal strains for alterations that would occur in PBP2x, and to compare the alterations found in laboratory mutants with those present in clinical isolates. It will also be important to localize the mutations in the PBP2x gene in cefotaxime-resistant mutants isolated independently from the one described here, and to determine whether there is a specific order of mutations that leads to decreased affinity for a given antibiotic.

$$
\begin{aligned}
& \text { S.p. } 2 \times \text { (576) SPAENPDFIL YVTVQQPEHY SGIQLGGEFAN PILER } \\
& \text { E.c. } 3 \text { (519) APASQPRFAL VVVINDPQAG KYYGGAVSAP VFGAI } \\
& \text { N.g. } 2 \text { (522) APAKNPRVIV AVTIDEPTAH GYYGGVVAGP } \\
& \text { S.p. } 2 \text { b (444) APSDNPQIAV AVVFPHNTNL TNGVGPSIAR DIINL. } \\
& \text { E.c. } 2 \text { (578) APYNNPQVAV AMILENGGAG PAVGTLMRQI LDHIM } \\
& \text { ** ** }
\end{aligned}
$$

Fig. 8. Amino acid sequences in different PBPs with homology to the regions neighbouring the mutations in $\mathrm{PBP} 2 \mathrm{x}$ of $\mathrm{C} 506$. Amino acids that appear conserved in most PBPs shown are marked by asterisks. Closed arrows point to the amino acids which are altered in PBPs of lowered $\beta$-lactam affinity. Open arrows indicate sites of mutations that inactivate PBP3 without interfering with $\beta$-lactam binding. 
were screened on plates containing $0.06 \mu \mathrm{g} \mathrm{ml}^{-1}$ cefotaxime, and erythromycin-resistant colonies were isolated using $5 \mu \mathrm{g} \mathrm{ml}^{-1}$ erythromycin. Transformation of $E$. coli strains was performed using gradient-purified plasmid DNA and $\mathrm{CaCl}_{2}$-treated cells (Brown et al., 1979).

\section{Preparation of pneumococcal chromosomal DNA}

Pneumococci were harvested by centrifugation at late-exponential growth phase. Cells were resuspended in 0.1 M EDTA, $0.005 \%$ deoxycholate, $0.01 \%$ SDS, $\mathrm{pH} 8.0$ and lysed during incubation at $37^{\circ} \mathrm{C}$ for $5 \mathrm{~min}$. After ethanol-precipitation, DNA fibres were collected and resuspended in $0.03 \mathrm{M}$ sodium citrate, $\mathrm{pH}$ 8.5. Following treatment with proteinase $\mathrm{K}\left(80 \mu \mathrm{g} \mathrm{ml}^{-1}\right)$ for 30 min at $37^{\circ} \mathrm{C}$, phenol-extraction and ethanol-precipitation, DNA was resuspended in $10 \mathrm{mM}$ Tris- $\mathrm{HCl}, 1 \mathrm{mM}$ EDTA, $\mathrm{pH} 7.5$, at about $200 \mu \mathrm{g} \mathrm{ml}^{-1}$.

\section{Isolation of plasmids from S. pneumoniae}

Plasmids were prepared from pneumococci essentially as described by Birnboim and Doly (1979).

\section{Southern blots and colony hybridization}

Restriction endonucleases were obtained from commercial sources. Restricted DNA fragments were eluted from agarose gels by the method of Vogelstein and Gillespie (1979). For Southern blot hybridizations, ${ }^{32} \mathrm{P}$ nick-translated DNA was used. Colony hybridization was performed with random primed DNA fragments using a non-radioactive labelling and detection kit (Boehringer: Mannheim, FRG).

\section{Sequencing of the PBP2x gene from $\mathrm{S}$. pneumoniae}

The $0.8 \mathrm{~kb}$ Eco RI-Bam $\mathrm{HI}$ insert of the recombinant plasmid pPG1 was subcloned into $\mathrm{M} 13 \mathrm{mp} 8 / \mathrm{mp} 9$. From the $1.8 \mathrm{~kb}$ EcoRI/Pst। insert of plasmid pCG6 (Fig. 3), unidirectional deletions were generated in the M13-derived vector phagescript SK using Exoll and S1 nuclease (Guo et al., 1983). The 2.4kb EcoRV/Dral insert of pCG8 (Fig. 3) was subcloned in pJDC9 and sequenced in the plasmid (Chen and Seeburg, 1985).

\section{Reagents and general techniques}

Restriction enzymes, T4 DNA ligase, and alkaline phosphatase were purchased from Boehringer (Mannheim, FRG), BRL (Gaithersburg, MD, USA) and New England Biolabs (Beverly, MA, USA) and used as described by the suppliers. Sequenase was from the United States Biochemical Corporation (Cleveland, $\mathrm{OH}$, USA). All molecular manipulations were performed using standard procedures (Maniatis et al., 1982) unless otherwise stated. Nucleotide sequencing was carried out by the chain-termination method (Sanger et al., 1977) using [ ${ }^{35}$ S]-dATP obtained from Amersham-Buchler (UK) in the sequenase reaction (Tabor and Richardson, 1987) and standard oligodeoxynucleotide primers.

\section{Assay of PBPS}

PBPs were visualized after incubation of cell lysates with $\left[{ }^{3} \mathrm{H}\right]$-propionylampicillin, followed by SDS-polyacrylamide gel electrophoresis and fluorography as described (Laible and Hakenbeck, 1987).

\section{Acknowledgements}

We thank D. Morrison for kindly providing plasmid pJDC9, and E. W. Goodell for critical reading of the manuscript. During this investigation, G.L. was on a short-term EMBO fellowship for three months; the kind help of Anne-Marie Gasc during this period is gratefully acknowledged. The work is Liège was supported by the Fonds de la Recherche Scientifique Médicale (contract no. 3.4507.83), an Action Concertée with the Belgian Government (convention 86/91-90), a convention with the Région wallonne (C2/C16/Conv.246/20428), the Fonds de Recherche de la Faculté de Médicine ULg, and a contract with the EEC (BAP0147-B).

\section{References}

Asoh, S., Matsuzawa, H., Ishino, F., and Strominger, J.L. (1986) Nucleotide sequence of the $p b p A$ gene and characteristics of the deduced amino acid sequence of penicillin-binding protein 2 of Escherichia coli K12. Eur J Biochem 160: 231-238.

Birnboim, H.C., and Doly, J. (1979) A rapid alkaline extraction procedure for screening recombinant plasmid DNA. Nucl Acids Res 7: 1513-1523.

Briese, T., Ellerbrok, H., Schier, H.-M., and Hakenbeck, R. (1988) Reactivity of anti- $\beta$-lactam antibodies with $\beta$-lactam-penicillinbinding protein complexes. In Antibiotic Inhibition of Bacterial Cell Surface Assembly and Function. Actor, P., Daneo-Moore, L., Higgins, M.L., Salton, M.R.J., and Shockman, G.D. (eds). Washington D.C.: American Society for Microbiology, pp. 404-409.

Broome-Smith, J.K., Edelman, A., and Spratt, B.G. (1983) Sequence of penicillin-binding protein 5 of Escherichia coli. In The Target of Penicillin. Hakenbeck, R., Labischinski, H., and Höltje, J.-V. (eds). Berlin: Walter de Gruyter, pp. 403-408.

Broome-Smith, J.K., Edelman, A., Yousif, S., and Spratt, B.G. (1985) The nucleotide sequences of the pon $A$ and pon $B$ genes encoding penicillin-binding proteins $1 \mathrm{~A}$ and $1 \mathrm{~B}$ of Escherichia coli K12. Eur J Biochem 147: 437-446.

Brown, M.G.M., Weston, A., Saunders, J.R., and Humphreys, G.O. (1979) Transformation of E. coli C600 by plasmid DNA at different phases of growth. FEMS Microbiol Lett 5: 219-222.

Chen, E.J., and Seeburg, P.H. (1985) Supercoil sequencing: a fast simple method for sequencing plasmid DNA. DNA 4: 165-170.

Chen, J.-D., and Morrison, D.A. (1987) Cloning of Streptococcus pneumoniae DNA fragments in Escherichia coli requires vectors protected by strong transcriptional terminators. Gene 55: 179-187.

Dowson, C.G., Hutchison, A., and Spratt, B.G. (1989) Extensive re-modelling of the transpeptidase domain of penicillin-binding protein $2 \mathrm{~B}$ of a penicillin-resistant South African isolate of Streptococcus pneumoniae. Mol Microbiol 3: 95-102.

Duez, C., Piron-Fraipont, C., Joris, B., Dusart, J., Urdea, M.S., Martial, J.A., Frère, J.-M., and Ghuysen, J.-M. (1987) Primary structure of the Streptomyces R61 extracellular DD-peptidase. 
1. Cloning into Streptomyces lividans and nucleotide sequence of the gene. Eur J Biochem 162: 509-518.

Edelman, A., Bowler, L.B., Broome-Smith, J.K., and Spratt, B.G. (1987) Use of a $\beta$-lactamase fusion vector to investigate the organization of penicillin-binding protein $1 \mathrm{~B}$ in the cytoplasmic membrane of Escherichia coli. Mol Microbiol 1: 101-106.

Engelman, D.M., Steitz, T.A., and Goldman, A. (1986) Identifying nonpolar transbilayer helices in amino acid sequences of membrane proteins. Annu Rev Biochem Biophys Chem 15: 321-353.

Garcia, P., Garcia, J.L., Garcia, E., and López, R. (1986) Nucleotide sequence and expression of the pneumococcal autolysin gene from its own promoter in Escherichia coli. Gene 43: 265-272.

Garnier, J., Osguthorpe, D.J., and Robson, B. (1978) Analysis of the accuracy and implications of simple methods for predicting the secondary structure of globular proteins. J Mol Biol 120: 97-120.

Goad, W.B., and Kanehisa, M.I. (1982) Pattern recognition in nucleic acid sequences. I. A general method for finding local homologies and symmetries. Nucl Acids Res 10: 247-263.

Guo, L.H., Yang, R.C.A., and Wu, R. (1983) An improved strategy for rapid direct sequencing of both strands of long DNA molecules cloned in a plasmid. Nucl Acids Res 11: 5521-5539.

Hakenbeck, R., and Kohiyama, M. (1982) Purification of penicillinbinding protein 3 from Streptococcus pneumoniae. Eur $J$ Biochem 127: 231-236.

Hakenbeck, R., Tarpay, M., and Tomasz, A. (1980) Multiple changes of penicillin-binding proteins in penicillin-resistant clinical isolates of Streptococcus pneumoniae. Antimicrob Agents Chemother 17: 364-371.

Hakenbeck, R., Ellerbrok, H., and Briese, T. (1986) Antibodies against the benzylpenicillin moiety as a probe for penicillinbinding proteins. Eur J Biochem 157: 101-106.

Hakenbeck, R., Tornette, S., and Adkinson, N.F. (1987) Interaction of non-lytic $\beta$-lactams with penicillin-binding proteins in Streptococcus pneumoniae. J Gen Microbiol 30: 755-760.

Hakenbeck, R., Briese, T., Ellerbrok, H., Laible, G., Martin, C., Metelmann, C., Schier, H.-M., and Tornette, S. (1988) Targets of $\beta$-lactams in Streptococcus pneumoniae. In Antibiotic Inhibition of Bacterial Cell Surface Assembly and Function. Actor, P., Daneo-Moore, L., Higgins, M.L., Salton, M.R.J., and Shockman, G.D. (eds) Washington, D.C.: American Society for Microbiology, pp. 390-399.

Hayashi, S., Hara, H., Suzuki, H., and Hirota, Y. (1988) Lipid modification of Escherichia coli penicillin-binding protein 3. J Bacteriol 170: 5392-5395.

Hedge, P.J., and Spratt, B.G. (1985a) Amino acid sustitutions that reduce the affinity of penicillin-binding protein 3 of Escherichia coli for cephalexin. Eur J Biochem 151: 111-121.

Hedge, P.J., and Spratt, B.G. (1985b) Resistance to $\beta$-lactam antibiotics by re-modelling the active site of an E. colipenicillinbinding protein. Nature 318: 478-480.

Joris, B., Ghuysen, J.-M., Dive, G., Renard, A., Dideberg, O., Charlier, P., Frère, J.-M., Kelly, J.A., Boyington, J.C., Moews, P.C., and Knox, J.R. (1988) The active-site-serine penicillinrecognizing enzymes as members of the Streptomyces R61 DD-peptidase family. Biochem J 250: 313-324.

Kelly, J.A., Knox, J.R., Moews, P.C., Moring, J., and Zhao, H.C. (1988) Molecular graphics: studying $\beta$-lactam inhibition in three dimensions. In Antibiotic Inhibition of Bacterial Cell Surface Assembly and Function. Actor, P., Daneo-Moore, L., Higgins, M.L., Salton, M.R.J., and Shockman, G.D. (eds). Washington, D.C.: American Society for Microbiology, pp. 261-267.
Kyte, J., and Doolittle, R.F. (1982) A simple method for displaying the hydropathic character of a protein. J Mol Biol 157: 105-132.

Lacks, S., and Hotchkiss, R.D. (1960) A study of the genetic material determining an enzyme activity in pneumococcus. Biochim Biophys Acta 39: 508-517.

Laible, G., and Hakenbeck, R. (1987) Penicillin-binding proteins in $\beta$-lactam-resistant laboratory mutants of Streptococcus pneumoniae. Mol Microbiol 1: 355-363.

Levèfre, J.C., Claverys, J.P., and Sicard, A.M. (1979) Donor deoxyribonucleic acid length and marker effect in pneumococcal transformation. J Bacteriol 138: 80-86.

Maniatis, T., Fritsch, F.E., and Sambrook, F. (1982) Molecular Cloning. A Laboratory Manual. Cold Spring Harbor, New York: Cold Spring Harbor Laboratory Press.

Méjean, V., Claverys, J.-P., Vasseghi, H., and Sicard, A.M. (1981) Rapid cloning of specific DNA fragments of Streptococcus pneumoniae by vector integration into the chromosome followed by endonucleolytic excision. Gene 15: 289-293.

Messing, I., and Vieira, J. (1982) A new pair of M13 vectors for selecting either strand of a double-digest restriction fragment. Gene 19: 269-276.

Messing, I., Crea, R., and Seeburg, P.H. (1981) A system for shotgun DNA sequencing. Nucl Acids Res 9: 309-321.

Nakagawa, J.I., Tamaki, S., Tomioka, S., Matsuhashi, M. (1984) Functional biosynthesis of cell wall peptidoglycan by polymorphic bifunctional polypeptides: penicillin-binding protein 1Bs of Escherichia coli with activities of transglycosylase and transpeptidase. J Biol Chem 259: 13937-13946.

Nakamura, M., Maruyama, I.N., Soma, M., Kato, J.-I., Suzuki, H., and Hirota, Y. (1983) On the process of cellular division in Escherichia coli: nucleotide sequence of the gene for penicillinbinding protein 3. Mol Gen Genet 191: 1-9.

Ottolenghi, E., and Hotchkiss, R.D. (1962) Release of genetic transforming agent from pneumococcal cultures during growth and disintegration. J Exp Med 116: 491-519.

Prats, H., Martin, B., Pognonec, P., Burger, A.-C., and Claverys, J.-P. (1985) A plasmid vector allowing positive selection of recombinant plasmids in Streptococcus pneumoniae. Gene 39: $41-48$.

Sanger, F., Nicklen, S., and Coulson, A.R. (1977) DNA sequencing with chain-terminating inhibitors. Proc Natl Acad Sci USA 74: 5463-5467.

Shockley, T.E., and Hotchkiss, R.D. (1970) Stepwise introduction of transformable penicillin resistance in pneumococcus. Genetics 64: 397-408.

Spratt, B.G. (1988) Hybrid penicillin-binding proteins in penicillinresistant strains of Neisseria gonorrhoeae. Nature 332: 173176.

Spratt, B.G., and Cromie, K.D. (1988) Penicillin-binding proteins of Gram-negative bacteria. Rev Infect Dis 10: 699-711.

Song, M.D. Wachi, M., Doi, M., Ishino, F., and Matsuhashi, M. (1987) Evolution of an inducible penicillin-target protein in methicillin-resistant Staphylococcus aureus by gene fusion. FEBS Lett 221: 167-171.

Stassi, D.L., and Lacks, S.A. (1982) Effect of strong promoters on the cloning in Escherichia coli of DNA fragments from Streptococcus pneumoniae. Gene 18: 319-328.

Tabor, S. and Richardson, C.C. (1987) DNA sequence analysis with a modified bacteriophage T7 DNA polymerase. Proc Natl Acad Sci USA 84: 4767-4771.

Tiraby, J.-G., and Fox, M.S. (1974) Marker discrimination and mutagen-induced alterations in pneumococcal transformation. Genetics 77: 449-458.

Todd, J.A., Roberts, A.N., Johnstone, K., Piggot, P.J., Winter, G., 
and Ellar, D. (1986) Reduced heat resistance of mutant spores after cloning and mutagenesis of the Bacillus subtilis gene encoding penicillin-binding protein 5. JBacteriol 167:257-264.

Tomioka, S., Ishino, F., Tamaki, S., and Matsuhashi, M. (1982) Formation of hypercrosslinked peptidoglycan with multiple crosslinkages by a penicillin-binding protein, 1A, of Escherichia coli. Biochem Biophys Res Commun 106: 1175-1182.

Vogelstein, B., and Gillespie, D. (1979) Preparative and analytical purification of DNA from agarose. Proc Natl Acad Sci USA 76: 615-619.

von Heijne, G. (1985) Signal sequences: the limits of variation. $J$ Mol Biol 184: 99-105.

Zighelboim, S., and Tomasz, A. (1980) Penicillin-binding proteins of multiple resistant South African strains of Streptococcus pneumoniae. Antimicrob Agents Chemother 17: 434-442. 
This document is a scanned copy of a printed document. No warranty is given about the accuracy of the copy. Users should refer to the original published version of the material. 